\title{
Phytopharmacological overview of Terminalia chebula Retz.
}

\author{
Agaath Hedina', Punniya Kotti², Juveriyah Kausar', Sivasamy' ${ }^{1}$, Vijaya Anand ${ }^{*}$ \\ 'Department of Human Genetics and Molecular Biology, Bharathiar University, Coimbatore, Tamil Nadu, INDIA. \\ 2Department of Biochemistry, Kanchi Shri Krishna College of Arts and Science, Kancheepuram, Tamil Nadu, INDIA.
}

\begin{abstract}
Phytotherapy is the traditional method used to cure many diseases. Various medicinal plants found in many parts of India are well known for their various medicinal values. The Terminalia chebula Retz. a native plant of Asia is found to have various properties like anti-oxidant and free radical scavenging activity, anti-carcinogenic activity, ant-imutagenic activity, anti-bacterial activity, anti-fungal activity, anti-viral activity, anti-diabetic, renoprotective activity, cardio-protective activity, anti-inflammatory and anti-arthritic activity. These properties of $T$. chebula discussed in this review are mainly due to the presence of various types of phytoconstituents.
\end{abstract}

Key words: Terminalia chebula, Anti-oxidant, Phytoconstituents, Free radical, Anti-fungal, Anti-carcinogenic, Renoprotective, Anti-arthritic, Anti-inflammatory.

Corresponding author: Dr. A. Vijaya Anand, Associate Professor and Head, Department of Human Genetics and Molecular Biology, Bharathiar University, Coimbatore-641 046, Tamil Nadu, INDIA.

Phone no: +919842525830

Email: avamiet@yahoo.com DOI : 10.5530/pj.2016.4.1

\section{INTRODUCTION}

The Siddha and Ayurveda treatments use plants to cure various diseases; ${ }^{1}$ they are the traditional method adopted in India before 5000 years. The use of plants in various treatments has drawn attention in recent years due to their accuracy in treatment and their reduced or absence of side effects. Treatments involving the use of chemically synthesized compounds have more severe side effects to patients other than curing the disease effectively. Terminalia chebula Retz. is one of the many traditional medicinal trees used to treat many diseased conditions. $T$. chebula under the family Combretaceae, a native plant in India and Southeast Asia, is widely cultivated in Taiwan. Its dried ripe fruit, also called as medicinal Terminalia fruit, has traditionally been used as a way to treat various ailments in Asia. ${ }^{2}$ T. chebula possesses a large number of different types of phytoconstituents which exhibits a number of medicinal activities. The fruit of the tree provides diverse health benefits and is a traditional medicine for household remedy against various human ailments over decades. ${ }^{3} T$. chebula has been widely used in Ayurveda, Unani and Homoeopathic medicine and has become an important part of modern medicine. The presence of the various phytochemicals like polyphenols, terpenes, anthocyanins, flavonoids, alkaloids and glycosides makes them a potent anti-oxidant, anti-fungal, antibacterial, anti-viral agents.

\section{BOTANICAL DESCRIPTION}

T. chebula is a native plant of Asia, found predominantly in Srilanka, Bangladesh, Egypt, Turkey, Tibet, Pakistan and various parts of India. This is a deciduous tree that grows up to $30 \mathrm{~m}$ in height with a crown shaped like a broad disk. ${ }^{4}$ This tree grows at the height of 1500-2000 m. They have sub-opposite or alternate leaves elliptic blades of 7-18×4.4-10 $\mathrm{cm}$. They have veins which are lateral and they occur as 6-12 pairs. T. chebula have monoecious flowers with unpleasant smell and are pale yellow in color. The unripen fruit is green in color and the ripe fruit is yellowish grey in color with the size of 1-2 inches. May to June is the time the flowers appear and July to December the fruits appear.

\section{ANTI-OXIDANT AND FREE RADICAL SCAVENGING ACTIVITY}

Compounds that can scavenge excessive free radicals in the body can hinder the process of carcinogenesis. The leaves, bark and fruit of
T. chebula possessed high anti-oxidant activity due to the presence of phenolics which is responsible for this activity. ${ }^{5}$ Aqueous form of the extract of T. chebula inhibited xanthine/xanthine oxidase activity and was also a scavenger of DPPH radicals. ${ }^{5}$ The poly-herbal formulation of T. chebula (Aller-7/ NR-A2) is found to inhibit the hemolysis and makes the lipopolysaccharide to release nitric oxide in an inhibited form. ${ }^{6}$ Acetone extract has stronger anti-oxidant activity than alpha-tocopherol and HPLC analysis with diode array detection indicated the presence of phenolic compounds such as hydroxybenzoic acid derivatives, hydroxyl cinnamic acid derivatives, flavonol aglycones and their glycosides. ${ }^{7}$

\section{ANTI-CARCINOGENIC ACTIVITY}

A group of researchers have reported the phenolics of $T$. chebula fruit have inhibitory action on cancer cell growth and found that tannic acid, ellagic acid and chebulinic were the growth inhibitory phenolics of T. chebula. ${ }^{8}$ Ethanol extract of T. chebula fruit inhibited cell proliferation and induce the death of the cell in a dose dependent manner in many malignant cell lines including breast cancer cell line of mouse (S115) and human (MCF-7), human osteosarcoma cell line (HOS-1), a non-tumorigenic immortalized human prostate cell line (PNT1A) and human prostate cancer cell (PC-3). ${ }^{9}$ Besides, acetone extract of bark and fruit powder of T. chebula have constituents with promising anti-carcinogenic activity. ${ }^{9}$

\section{ANTI-MUTAGENIC ACTIVITY}

Anti-mutagenic activity of aqueous extract and hydrolyzable tannins from T. chebula in Salmonella typhimurium has been well documented. ${ }^{10}$ The aqueous extract of $T$. chebula inhibits gamma radiation induced strand breaks formation in plasmid PBR322 DNA. ${ }^{11}$ The administration of aqueous extract of T. chebula prior to whole body irradiation of mice resulted in a reduction of peroxidation of membrane lipids in the mice liver and a decrease in radiation induced errors to DNA. It also protected the human lymphocytes from the harmful gamma radiation-induced damage to DNA exposed in vitro. ${ }^{12}$ T. chebula showed chemo preventive effects on toxicity, nickel chloride -induced renal oxidative stress, and cell proliferation response in male Wistar rat.

\section{ANTI-BACTERIAL ACTIVITY}

T. chebula showed anti-bacterial activity against both Gram-positive and Gram-negative human pathogenic bacteria. ${ }^{13,14}$ Ethanedioic acid and 
ellagic acid isolated from T. Chebula fruit extract had strong anti-bacterial activity against intestinal bacteria, Clostridium perfingens and Escherichia coli. ${ }^{15}$ It is effective against Helicobactor pyroli by inhibiting the urease activity, and ubiquitous bacterium which cause stomach cancer, ulcers and gastritis. ${ }^{14}$ The methicillin-resistant Staphylococcus aureus when treated with the extract of $T$. chebula showed decreased growth and activity thereby confirming the anti-bacterial activity. The ripe seeds of $T$. chebula also have strong anti-bacterial activity against $S$. aureus. The aqueous extract of T. chebula strongly inhibited the growth of Streptococcus mutants, salivary bacteria. ${ }^{16}$

\section{ANTI-FUNGAL ACTIVITY}

An aqueous extract of $T$. chebula showed anti-fungal activity against a number of dermatophytes and yeasts. It's activity is effective against the pathogenic yeast Candida albicans and dermatophytes Epidermophyton floccosum, Microsporumgy pseum and Trichophyton rubrum. ${ }^{17}$ Methanol extract of $T$. chebula have anti-candidal activity which acts against clotrimazole resistant Candida albicans. Anti-fungal activity against Trichophyton glabrata exhibited by seed extracts. ${ }^{18}$

\section{ANTI-VIRAL ACTIVITY}

T. chebula fruits used for four immunodeficiency virus HIV-1 (type 1) integrase inhibitors, GA (I) and three galloyl glucoses (II-IV). Their galloyl moiety plays an important role for inhibition of 3'-processing of HIV-1 integrase of the compounds. ${ }^{19}$ T. chebula also exhibit retroviral reverse transcriptase inhibitory activity. ${ }^{20}$ It protects epithelial cells against influenza a virus; supporting its use for aiding in treatment of acute respiratory infections..$^{21}$ It also showed the therapeutic activity against herpes simplex virus both in vitro and in vivo tests. ${ }^{22}$ These findings encouraged a team of Japanese researchers to investigate T. chebula effect on human cytomegalovirus (CMV). The replication of human cyto-magalo virus in AIDS is found to be inhibited by the extract of T. chebula and also in preventing CMV disease.

\section{ANTI-DIABETIC AND RENOPROTECTIVE ACTIVITY}

In streptozotocin induced diabetic rats T. chebula fruit and seeds showed dose dependent reduction in blood glucose both in short term and long term study and also had renoprotective activity. The high blood sugar level is reduced to normal by using the extract of T. chebula. ${ }^{23,24}$

\section{CARDIOPROTECTIVE ACTIVITY}

Pretreatment with the extract of T. chebula was found to ameliorate the consequence of isoproterenol on the formation of lipid peroxide and also retained the activities of the diagnostic marker enzymes in isoproterenol induced myocardial damage in rats. ${ }^{25}$ Its pericap has been reported to have cardioprotective activity which is showed in isolated frog heart model.

\section{ANTI-INFLAMMATORY AND ANTI-ARTHRITIC ACTIVITY}

Aqueous extract of dried fruit of T. chebula demonstrated inhibition of inducible nitric oxide synthesis which shows anti-inflammatory activity. ${ }^{26}$ Chebulagic acid obtained from immature seeds of $T$. chebula significantly suppressed the onset and progression of collagen induced arthritis in mice. ${ }^{27}$ Polyherbal formulation (Aller-7) containing T. chebula exhibited a dose dependent anti-inflammatory activity against Freund's adjuvant induced arthritis in rats. ${ }^{28}$

\section{CONCLUSION}

Among all the rapidly healing chemical medicines available, a large number of populations in the whole world are still using plants to cure disease. The T. chebula with its numerous pharmacological activities found its rightful place in traditional medicine. More biochemical tests are yet to be conducted to find more uses and potential value of T. chebula. This can lead to a rapid emergence of the use of plant extracts to cure many diseases without causing any harm to the patient thereby leading to a healthy environment.

\section{ACKNOWLEDGEMENT}

None.

\section{CONFLICT OF INTEREST}

No funding source and there is no conflict of interest.

\section{ABBREVIATION USED}

DPPH: 1,1-Diphenyl-2-picryl-hydrazyl; HPLC: High Performance Liquid Chromatography; AIDS: Acquired Immune Deficiency Syndrome.

\section{REFERENCES}

1. Beusher N, Bodinet C, Neumann-Haefelin D, Marston A, Hostettmann K. Antiviral activity of African medicinal plants. J Ethnophar-macol. 1994;42(2):101-9.

2. Hua-yew C, Ta-chan L, Kuo-hua Y, Chien-min Y, Chun-ching L. Anti-oxidant and Free Radical Scavenging Activities of Terminalia chebula. Boil Pharma Bull. 2003;26(9):1331-5.

3. Khare CP. Indian medicinal plants: An illustrated dictionary. Berlin, SpringerVerlag. 2007;652-3.

4. Chattopadhyay RR, Bhattacharyya SK. Plant Review Terminalia chebula. Pharmacognos. Rev. 2007;23:145-50.

5. Naik GH, Priyadarsini KI, Naik DB, Gangabhagirathi R, Mohan H. Studies on the aqueous extract of Terminalia chebula as a potent anti-oxidant and a probable radioprotector. Phytomedicine. 2004;11(6):530-8.

6. Mahesh R, Bhuvana S, Begum VM. Effect of Terminalia chebula aqueous extract on oxidative stress and anti-oxidant status in the liver and kidney of young and aged rats. Cell Biochem Funct. 2009;27(6):358-63.

7. Chen X, Sun F, Ma L, Wang J, Qin H, Du G. In vitro evaluation on the anti-oxidant capacity of triethylchebulate, an aglycone from Terminalia chebula Retz. fruit. Indian J Pharmacol. 2011;43(3):320-3.

8. Saleem M, Hushum P, Harkonen K, Pihlaja. Inhibition of cancer cell growth by crude extract and phenolics of Terminalia chebula fruit. J Ethnopharmacol. 2002;81(3):327-36

9. Reddy DB, Reddy TC, Jyotsna G, Sharan S, Priya N, Lakshmipathi V. Chebulagic acid, a COX-LOX dual inhibitor isolated from the fruits of Terminalia chebula Retz. induces apoptosis in COLO-205 cell line. J Enthnopharmacol. 2009;124(3):506-12

10. Grover IS, Bala S. Anti-mutagenic activity of Terminalia chebula (myroblan) in Salmonella typhimurium. Indian J ExpBiol. 1992;30(4):339-41.

11. Naik GH, Priyadarsini KI, Naik DB, Gangabhagirathi $\mathrm{R}$ and Mohan $\mathrm{H}$. Studies on the aqueous extract of Terminalia chebula as a potent anti-oxidant and a probable radioprotector. Phytomedicine. 2004;11(6):530-8.

12. Gandhi NM, Nayar CKK. Radiation protection by Terminalia chebula some mechanistic aspects. Mol Cell Biochem. 2005;277(1-2):43-8.

13. Khan KH, Jain SK. Regular intake of Terminalia chebula can reduce the risk of getting typhoid fever. Adv Biotech. 2009;8(9):10-5.

14. Malckzadeh F, Ehsanifar $H$, Shahamat N, Levin M, Colwell RR. Anti-bacterial activity of black myrobalan (Terminalia chebula Retz.) against Helicobactor pyroli. Int J Anti-microb Agent. 2001;18(1):85-8.

15. Kim HG, Cho JH, Jeong EY, Lim JH, Lee SH, Lee HS. Growth inhibitory activity of active component from Terminalia chebula fruits against intestinal bacteria. J Food Prot. 2006;69(9):2205-9

16. Sato $Y$, Oketani $H$, Singyouchi $K$, Ohtsubo T, Kihara M, Shibata $H$. Extraction and purification of effective anti-microbial constituents of Terminalia chebula Retz. against methicillin resistant Staphylococcus aureus. Bull Pharm Bull. 1997;20(4):401-4

17. Barazani VO, Sathiyomoorthy P, Shalev R, Vardy D, Golan GA. Screening of SouthIndian medicinal plants for anti-fungal activity. Phyther Res. 2003;17(9):1123-5. 
18. Bonjar GH. Inhibition of Clotrimazole-resistant Candida albicans by plants used in Iranian folkloric medicine. Fitoterapia. 2004

19. Jeong AHN, Kim CY, Lee JS, Kim TG, Kim SH, Lee CK. Inhibition of HIV-1 integrase by galloyl glucoses from Terminalia chebula and flovonol glycoside gallates from Euphorbia pekinensis. Plant Med. 2002;68(5):457-9.

20. Lee D, Boo K, Woo J, Duan F, Lee K, Kwon T. Anti-bacterial and Anti-viral activities of extracts from Terminalia chebula barks. J Korean Soc Appl Biol Chem. 2011;52(2):295-8.

21. Badmaev V, Nowakowski M. Protection of epithelial cells against influenza $A$ virus by plant derived biological response modifier Ledretan-96. Phytother Res. 2000;44(4):245-9

22. Kurowa M, Nagasaka K, Hirabayashi T, Uyama S, Sato H, Kagiyama T. Efficacy of traditional herbal medicines in combination with acyclovir against Herpes Simplex Virus-1 infection in vitro and in vivo. Anti-viral Res. 1995;27(1-2):19.

23. Sabu MC, Kuttan R. Anti-diabetic activity of medicinal plants and its relationship with their anti-oxidant property. J Ethnopharmacol. 2002;81(2):155-60.
24. Rao NK, Nammi S. Anti-diabetic and renoprotective effects of the chloroform extract of Terminalia chebula seeds in streptozotocin-induced diabetic rats. BMC Complement Altern Med. 2007;7:6-11.

25. Suchalatha S, Shyamadevi CS. Protective effect of Terminalia chebula against experimental myocardial injury induced by isoproterenol. Indian J Exp Biol. 2004;42(2):174-8.

26. Moeslinger T, Friedl R, Volf I, Brunner M, Koller E, Spieckermann PG. Inhibition of inducible nitric oxide synthesis by the herbal preparation Padma 28 in macrophage cell line. Can J Physiol Pharmacol. 2000;78(11):861-6.

27. Nair V, Singh S, Gupta YK. Anti-arthritic and disease modifying activity of Terminalia chebula Retz. In experimental models. J Pharm Pharmacol. 2010; 62(12):1801-6.

28. Pratibha N, Saxena VS, Amit A, D'Souza P, Bagchi M, Bagchi D. Anti-inflammatory activities of Aller-7, a novel polyherbal formulation for allergic rhinitis. Int J Tissue React. 2004:26(1-2):43-51.

\section{PICTORIAL ABSTRACT}

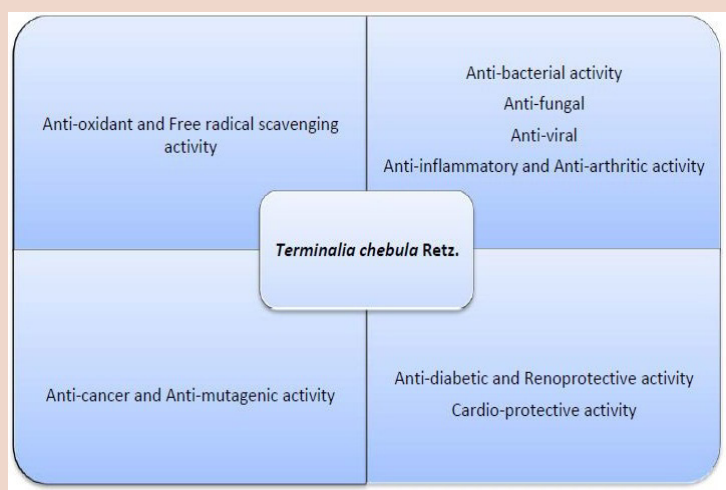

\section{SUMMARY}

- This review confirmed the ability of Terminalia chebula Retz.

- Terminalia chebula exhibit anti-microbial, anti-diabetic, cardio-protective, anti-oxidant and anti-cancer activities.

- Its support the traditional uses Terminalia chebula.

\section{ABOUT AUTHOR}

Dr. A. Vijaya Anand: Associate Professor and Head, Department of Human Genetics and Molecular Biology, Bharathiar University, Coimbatore, Tamil Nadu, India. He has published multiple scientific articles in international journals. He is currently engaged in the field of phytopharmacology, neurogenetics, medical genetics and clinical biochemistry. 